\title{
Retro Aortic Left Renal Vein: A Case Report and Brief Literature of Review
}

\author{
Susan Mohammadi ${ }^{1}$, Mohammad Sadegh Gholami Farashah ${ }^{2}$, Negin Frounchi ${ }^{3}$, Hamed Shoorei ${ }^{4 *}$ and \\ Mohammad Bakhtiar Hesam Shariati ${ }^{2 *}$ \\ ${ }^{1}$ Department of Radiology, Faculty of Medicine, Kurdistan University of Medical Sciences, Iran \\ ${ }^{2}$ Department of physician, Faculty of Medicine, Tabriz University of Medical Sciences, Iran
}

${ }^{3}$ Department of Anatomical Science, Faculty of Medicine, Tabriz University of Medical Sciences, Iran

Received: February 15, 2018; Published: March 21, 2018

*Corresponding author: Mohammad Bakhtiar Hesam Shariati, Tabriz University of Medical Sciences, Faculty of Medicine, Tabriz, Iran, Tel: 989188716993; Fax: +98-41-33342086, Email: Shariatim@tbzmed.ac.ir

Hamed Shoorei, Tabriz University of Medical Sciences, Faculty of Medicine, Tabriz, Iran, Tel: 989357551569; Fax: +98-41-33342086, Email: h.shoorei@gmail.com

\section{Abstract}

Retro aortic left renal vein (RLRV) is a relatively uncommon condition in which the left renal vein pass behind the abdominal aorta. It has been reported that it occurs in 1.8-2.4 of population. RLRV can lead to various symptoms including hematuria, varicocele, ureteropelvic junction obstruction, left flank pain, and inguinal pain. RLRV has been divided into four groups based on the type of blood drainage. However, in this case report, we present a case of RLRV which was diagnosed by ultrasonography and computed tomography scan.

Keywords: Retro aortic left renal vein; Vascular Variation

\section{Introduction}

One of the most important anomalies regarding inferior vena cava (IVC) and its branches is retro aortic left renal vein (RLRV) which occurs in 1.8-2.4 of population [1]. RLRV can drain into inferior vena cava (IVC) at same level of normal left renal vein or enters into IVC, of course, at a lower level where IVC joins to the common iliac veins [1]. Compression of the RLRV between the aorta and the vertebra is known to be the cause of urological problems such as hematuria, varicocele, and ureteropelvic junction obstruction (UPJO) [2]. It has been reported that microscopic hematuria can be resulted from increasing pressure of the renal vein $[1,2]$.

On the other hand, if the space between the aorta and the vertebra decrease, the posterior "nutcracker phenomenon" can occur because of compression of the RLRV [2]. In the present case report, RLRV was diagnosed by Magnetic Resonance Imaging (MRI), computed tomography (CT) scan and ultrasonography. Moreover, embryological events causing the formation of this anomaly and a brief review of the literature have been discussed.
Case Report

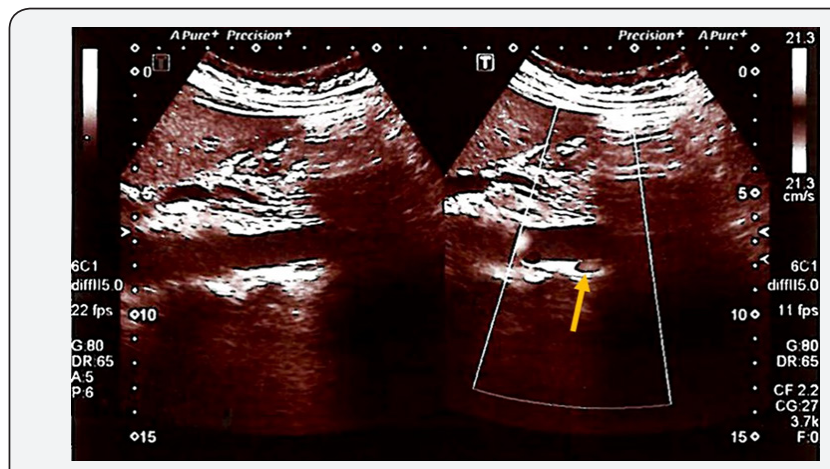

Figure 1: Ultrasonography demonstrates retro aortic left renal vein (RLRV) (yellow arrow).

A 38-year-old male was referred to the radiology clinic because he had periodic left flank pain without a history of trauma, kidney stone, kidney and urinary tract infections and other diseases. He suffered from these conditions for several months. There were no fever and trembling. Vital signs, 
including blood pressure, blood oxygen level, respiratory and heart rate were normal. Blood and urine tests showed normal levels of inflammatory factors, creatine, as well as urea. The ultrasonography and CT scan (as contrast-enhance) of abdomen and pelvis were performed for diagnosis. Obtained images revealed that the left renal vein located between the abdominal aorta and lumbar vertebral body (Figures $1 \& 2$ ). The other abdominal-pelvic organs had the normal position. The patient was informed about the process of medical imaging and the consent was obtained from him.

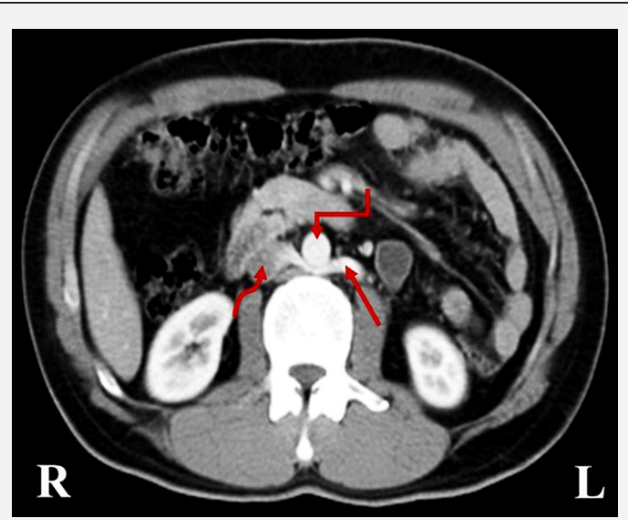

Figure 2: Axial contrast-enhanced computed tomography (CT) image revealed RLRV (red arrow) passing posteriorly to the abdominal aorta (red elbow arrow), joining inferior vena cava (red curved arrow).

\section{Discussion and Conclusion}

One of the important vascular variations in the body is the RLRV, which, if detects before surgery, especially retroperitoneal surgeries, can prevent unwanted incidences such as severe bleeding [3]. RLRV refer to a situation in which the left renal vein passing behind the abdominal aorta and drains the left kidney blood to the IVC [1-3]. However, embryo logically, the development of the renal veins is a part of the complex developmental process of the IVC. The process starts from the 4th week of conception and ends at about the 8th week [4]. During the development of the inferior vena cava, a vein ring that surrounds the aorta is formed $[4,5]$.

On the other hand, if during development, the anterior portion of the vein ring remains, it will become normal left renal vein, while, if the posterior part remains, the RLRV will be created [6]. For the first time, the RLRV observed in 1895 in an autopsy survey and first clinical diagnosis of RLRV was observed by Lord et al. [7] during a surgery in related to an abdominal aortic aneurysm in 1964. One study reported the various symptoms of the RLRV in 9 patient ( 5 male and 4 female); They reported showed that 5 of the 9 patients had microscopic hematuria, 4 of the 9 patients had left flank pain, 1 of the 5 male patients had inguinal pain, and gross hematuria was observed in 1 of the 9 patients; Furthermore, the concomitant diseases were UPJO in 2 of the 9 patients and varicocele in 2 of the 5 male patients [2].

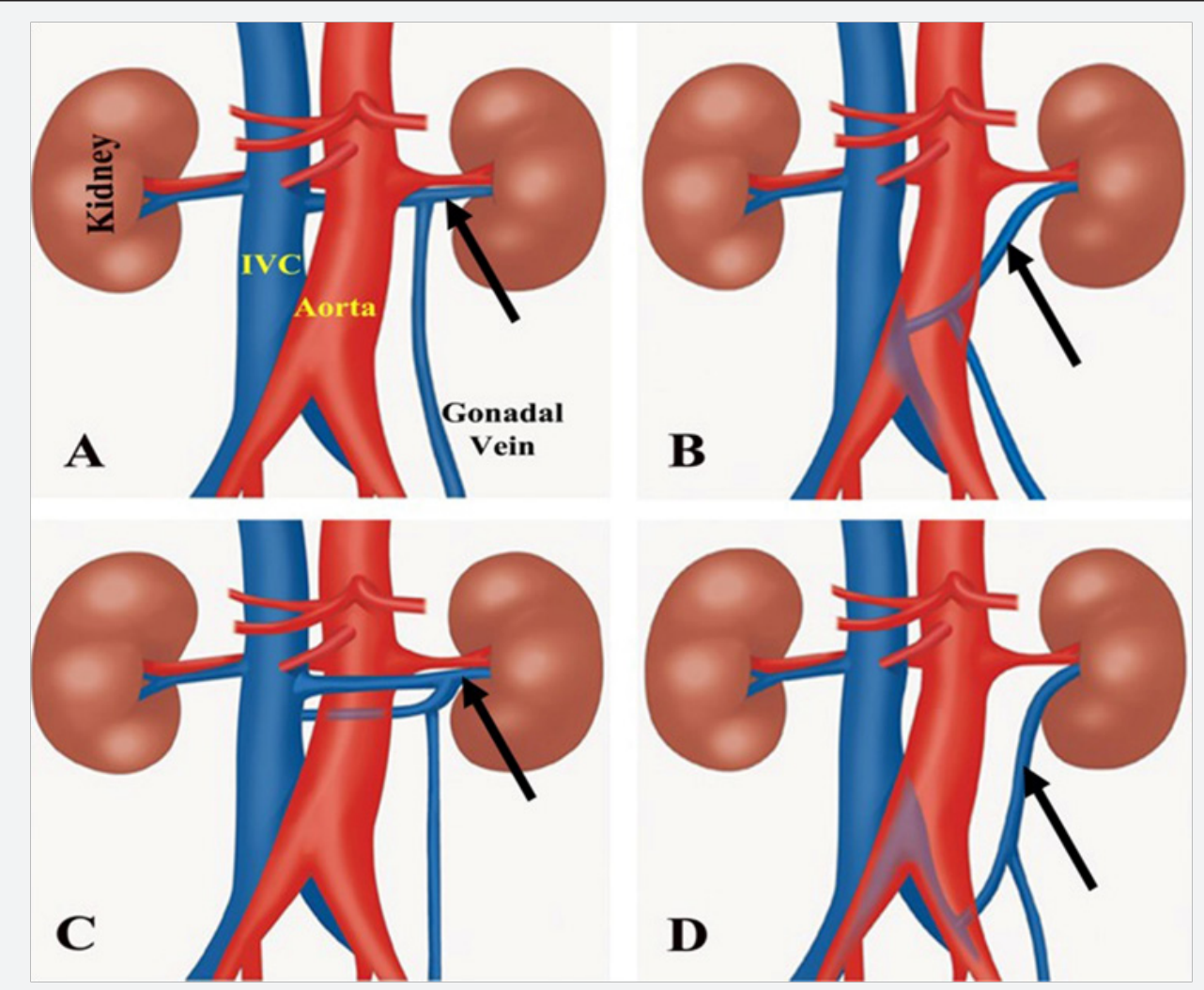

Figure 3: Schematic illustration of four different types of retro aortic left renal vein anomalies. (A) Type I, (B) Type II, (C) Type III, (D) Type IV. Black arrows show different types of RLRV. 
RLRV is classified in 1995 by Hoeltl et al. [8] into two types, I and II. In type I, RLRV has orthotropic status, while, in type II, the left renal vein moves downward combined with the lumbar and gonadal (testicular or ovarian) veins before passes through behind the aortic artery and drains into the inferior vena cava [8]. Our case seems to be classified as type I. In another classification, which was present in 2007, the RLRV has been divided into four groups based on the type of blood drainage [9] (Figure 3). Type I: drainage of RLRV to the inferior vena cava occurs in the orthotropic status; Type II: the RLRV drain to the ICV at the level of the L4-L5; Type III: the LRV, which consists of anterior and posterior branches, therefore, the vein is called collar LRV; Type IV: the RLRV drains into the left common iliac vein [9]. Our suggestion is that the present case is classified as type I. Imaging techniques such as CT scan, MRI, and ultrasonography are useful methods to diagnose the RLRV. Unaware of the existence of RLRV can cause irreparable events such as bleeding and even death during the retroperitoneal surgery of the abdomen [10]. Surgeons prefer the left renal vein in renal transplantation because of its longer length. Hence, it is important to know the course of the left renal vein whether it is preaortic or not. It is also important to be aware of anomalies of the renal vein for distinctive diagnosis of retroperitoneal tumors, retroperitoneal lymph node pathologies, and aortic dissection [11]. However, during any operations, lack of knowledge about anatomical variations, for example, variations in the peripheral nerves, organs, etc., may make a hard situation for surgeons and leads to a possible mistake during surgery [12-14].

\section{References}

1. Brancatelli G, Galia M, Finazzo M, Sparacia G, Pardo S, et al. (2000) Retro aortic left renal vein joining the left common iliac vein. European Radiology 10(11): 1724-1725.

2. Nam JK, Park SW, Lee SD, Chung MK (2010) The clinical significance of a retro aortic left renal vein. Korean J Urol 51(4): 276-280.

3. Dilli A, Ayaz UY, Karabacak OR, Hekimoglu B (2011) Retroaortic left renal vein in a case of left adrenal adenoma: radiological findings. Case Rep Med 2011: 867895.
4. Larsen WJ (2001) Human embryology. ( $5^{\text {th }}$ edn) Churchill Livingstone, UK, pp. 576.

5. Lehman EP (1938) Spontaneous arteriovenous fistula between the abdominal aorta and the inferior vena cava: case report presented in discussion of the paper by doctors reid and mcguire on arteriovenous aneurysms. Ann Surg 108(4): 694-700.

6. Fassiadis N, Buchanan EM, Wilkins J, Jones K, Edmondson R (2008) Retro aortic left renal vein fistula masquerading as pelvic congestion syndrome: case report. International Journal of Surgery 6(6): e77-e79.

7. Suzuki M, Collins GM, Bassinger GT, Dilley RB (1976) Aorto-left renal vein fistula: an unusual complication of abdominal aortic aneurysm. Annals of surgery 184(1): 31-34.

8. Hoeltl W, Hruby W, Aharinejad S (1990) Renal vein anatomy and its implications for retroperitoneal surgery. The Journal of urology 143(6): 1108-1114.

9. Karaman B, Koplay M, Özturk E, Basekim C, Ogul H, et al. (2007) Retro aortic left renal vein: multidetector computed tomography angiography findings and its clinical importance. Acta Radiol 48(3): 355-360.

10. Hsieh CL, Tiao WM, Chou YH, Tiu CM (2012) Retro aortic left renal vein: Three case reports. Journal of Medical Ultrasound 20(2): 115118.

11. Karkos CD, Bruce IA, Thomson GJ, Lambert ME (2001) Retro aortic left renal vein and its implications in abdominal aortic surgery. Annals of vascular surgery 15(6): 703-708.

12. Majdi A, Eyni H, Ghorbani S, Dolatkhah MA, Salimnejad R, et al. (2017) Anatomical Variation of the Anterior Cutaneous Branch of Femoral Nerve: A Case Report. Open Access J Surg 2(1): 1-2.

13. Nasrabadi HT, Abedelahi A, Shoorei H, Shokoohi M, Salimnejad R, et al. (2017) A variation of Musculocutaneous nerve without piercing the coracobrachialis muscle while communicating to the median nerve: A case report and literature review. International journal of surgery case reports 41: 453-455.

14. Salimnejad R, Momtaz AH, Ghoreishi Z, Shokoohi M, Bolandhemmat D, et al. (2018) Thyroglossal duct cyst coexisting with a fistulous tract: A rare case report and literature review. Journal of Pediatric Surgery Case Reports 28: 59-61.
Your next submission with Juniper Publishers will reach you the below assets

- Quality Editorial service

- Swift Peer Review

- Reprints availability

- E-prints Service

- Manuscript Podcast for convenient understanding

- Global attainment for your research

- Manuscript accessibility in different formats ( Pdf, E-pub, Full Text, Audio)

- Unceasing customer service

Track the below URL for one-step submission https://juniperpublishers.com/online-submission.php 